\title{
Mean Square Cordial Labeling of Some Cycle Related Graphs
}

\author{
S Dhanalakshmi ${ }^{1}$, N.Parvathi ${ }^{2}$ \\ ${ }^{1}$ Department of mathematics, Faculty of Engineering and technology, SRM IST, Chennai -600089, India \\ ${ }^{2}$ Department of mathematics , Faculty of Engineering and technology, SRM IST, Chennai -600089,India \\ *Corresponding author Email :parvathi.n@ktr.srmuniv.ac.in
}

\begin{abstract}
In this paper we investigate the Mean square cordial labeling for some cyclic graphs like Helm graph $\mathrm{H}_{\mathrm{p}}$, Closed helm graph $\mathrm{CH}_{\mathrm{p}}$, Gear graph $\mathrm{G}_{\mathrm{p}}$, Sunlet graph $\mathrm{SL}_{\mathrm{p}}$, Fan graph $\mathrm{F}_{1, \mathrm{p}}$ and $\mathrm{C}_{\mathrm{p}} \odot \mathrm{nK} \mathrm{K}_{1}$.

Keywords: Mean square cordial labeling, Closed helm graph, Gear graph, Sunlet graph.
\end{abstract}

\section{Introduction}

Many graph labeling [1] techniques have been discussed by different researchers and it is still getting enrichment due to its broad range of applications in various fields like electrical circuit theory, social psychology, addressing communication network Systems, finding optimal circuit layouts, channel assignment process etc..For basics terms and notations we follow Harary[2]. Cahit initiated the Cordial labeling [3] and Ponraj and et al[4] paved the way to mean cordial labeling of a graph .Mean square cordial labeling (MSCL)was first introduced by A.Nellai murugan et al and this labeling technique is applied for few classes of graphs[5].In addition to that they discussed that some path ,tree and cycle related graph admits MSCL [6],[7]. Along with that MSCL of some acyclic graphs and upper approximations [8] were studied by Dhanlakshmi et al . In this paper we investigate the MSCL for some cyclic graphs like Helm graph $\mathrm{H}_{\mathrm{p}}$, Closed helm graph $\mathrm{CH}_{\mathrm{p}}$, Gear graph $\mathrm{G}_{\mathrm{p}}$, Sunlet graph $\mathrm{SL}_{\mathrm{p}}$, Fan graph $\mathrm{F}_{1, \mathrm{p}}$ and $\mathrm{C}_{\mathrm{p}} \odot \mathrm{nK}_{1}$.

\section{Preliminaries}

A.Nellai murugan and et al defined "A Mean Square Cordial labeling(MSCL) of a Graph $\mathrm{G}(\mathrm{V}, \mathrm{E})$ with $\mathrm{p}$ vertices and q edges is a bijection from $\mathrm{V}$ to $\{0,1\}$ such that each edge uv is assigned the label $\left(\left(\sqrt{f}(u)^{2}+f(v)^{2}\right) / 2\right)$ where $\lceil x\rceil(\operatorname{ceil}(\mathrm{x}))$ is the least integer greater than or equal to $\mathrm{x}$ with the condition that the number of vertices labeled with 0 and the number of vertices labeled with 1 differ by at most 1 and the number of edges labeled with 0 and the number of edges labeled 0 and the number of edges labeled with 1 differ by at most 1".

\section{Main results}

Theorem: 3.1 MSCL of a Helm graph $H_{p}$ when $p$ is odd $p \geq 3$.

Proof: Consider a helm graph $\mathrm{H}_{\mathrm{p}}$ be $\mathrm{G}$.

Let the vertex set and edge set as V $(G)=\left\{u 0, v_{i}, u i, 1 \leq i \leq p\right\}$ and $\mathrm{E}(\mathrm{G})=\left\{\left[\left(\mathrm{u}_{0} \mathrm{u}_{\mathrm{i}}\right): 1 \leq \mathrm{i} \leq \mathrm{p}\right] \cup\left[\left(\mathrm{u}_{\mathrm{i}} \mathrm{v}_{\mathrm{i}}: 1 \leq \mathrm{i} \leq \mathrm{p}\right] \cup\left[\left(\mathrm{u}_{\mathrm{i}} \mathrm{u}_{\mathrm{i}+1}\right): 1 \leq \mathrm{i} \leq \mathrm{p}-1\right]\right.\right.$ $\left.\cup\left[\left(u_{1} u_{p}\right): 1 \leq i \leq p\right]\right\}$ where $u_{0}, u_{i}$ and $v_{i}$ be the centre vertex ,vertices on a cycle and pendent vertices respectively.

Consider the elements of the vertex set maps either 0 or 1 .

$$
\begin{aligned}
& f\left(u_{0}\right)=0 \\
& f\left(u_{i}\right)=0,\left\{\begin{array}{l}
1 \leq i \leq \frac{p+1}{2} \\
\frac{p+3}{2}<i \leq p
\end{array}\right.
\end{aligned}
$$

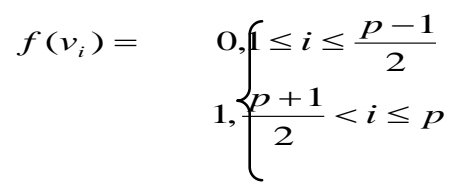

The edge labeling pattern of the above vertex labeling is as follows

$$
\begin{aligned}
& f\left(u_{\mathrm{o}} \boldsymbol{u}_{i}\right)=\left\{\begin{array}{l}
, 1 \leq i \leq \frac{p+1}{2} \\
1, \frac{p+3}{2}<i \leq p
\end{array}\right. \\
& f\left(u_{i} u_{i+1}\right)=\left\{\begin{array}{l}
\left\{, 1 \leq i \leq \frac{p-1}{2}\right. \\
1, \frac{p+1}{2}<i \leq p
\end{array}\right. \\
& f\left(u_{i} v_{i}\right)=\left\{\begin{array}{l}
, 1 \leq i \leq \frac{p-1}{2} \\
1, \frac{p+1}{2}<i \leq p
\end{array}\right. \\
& f\left(u_{1} u_{p}\right)=1 \text {, }
\end{aligned}
$$

It is very clear that the above labeling pattern proved that the 
difference between the vertices and edges labeled with 0 and 1 differ atmost by 1 .

Hence helm graph $\mathrm{H}_{\mathrm{p}}$ admits MSCL when $\mathrm{m}$ is odd $\forall p \geq 3$.

Example 3.1: MSCL of a Helm graph $\mathrm{H}_{5}$ is shown in the Fig 1

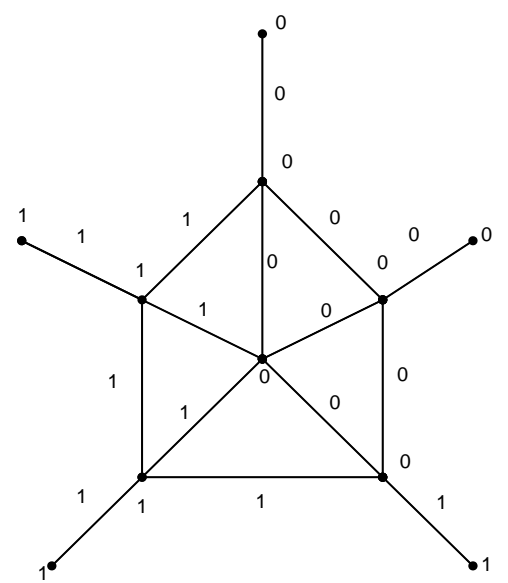

Fig 1:

Theorem: 3.2 MSCL of a closed helm graph $\mathrm{CH}_{p} \quad \forall p \geq 2$.

Proof: Consider a closed helm graph $\mathrm{P}_{\mathrm{p}} \odot \mathrm{K}_{1}$ be $\mathrm{G}$.

Let $V(G)=\left\{u_{0}, v_{i}, u_{i}: 1 \leq i \leq p\right\}$ and $E(G)=\left\{\left[\left(u_{0} u_{i}\right): 1 \leq i \leq p\right] \cup\right.$ $\left[\left(\mathrm{u}_{\mathrm{i}} \mathrm{v}_{\mathrm{i}}: 1 \leq \mathrm{i} \leq \mathrm{p}\right] \cup\left[\left(\mathrm{v}_{\mathrm{i}} \mathrm{v}_{\mathrm{i}+1}\right): 1 \leq \mathrm{i} \leq \mathrm{p}-1\right] \cup\left[\left(\mathrm{u}_{\mathrm{i}} \mathrm{u}_{\mathrm{i}+1}\right): 1 \leq \mathrm{i} \leq \mathrm{p}-1\right] \cup\right.$ $\left.\left[\left(\mathrm{v}_{1} \mathrm{v}_{\mathrm{p}}\right): 1 \leq \mathrm{i} \leq \mathrm{p}\right] \cup\left[\left(\mathrm{u}_{1} \mathrm{u}_{\mathrm{p}}\right): 1 \leq \mathrm{i} \leq \mathrm{p}\right]\right\}$ where $\mathrm{u}_{0}, \mathrm{u}_{\mathrm{i}}$ and $\mathrm{v}_{\mathrm{i}}$ be the centre vertex vertices on a inner cycle and vertices on a outer cycle respectively.

Consider the elements of the vertex set maps either 0 or 1 .

$\mathrm{f}\left(\mathrm{u}_{0}\right)=0$,

$\mathrm{f}\left(\mathrm{u}_{\mathrm{i}}\right)=0,1 \leq \mathrm{i} \leq \mathrm{p}$

$\mathrm{f}\left(\mathrm{v}_{\mathrm{i}}\right)=1,1 \leq \mathrm{i} \leq \mathrm{p}$

The edge labeling pattern of the above vertex labeling is as follows

$\mathrm{f}\left(\mathrm{u}_{0} \mathrm{u}_{\mathrm{i}}\right)=0,1 \leq \mathrm{i} \leq \mathrm{p}$

$\mathrm{f}\left(\left(\mathrm{u}_{\mathrm{i}} \mathrm{u}_{\mathrm{i}+1}\right)=0,1 \leq \mathrm{i} \leq \mathrm{p}-1\right.$

$\mathrm{f}\left(\mathrm{u}_{\mathrm{i}} \mathrm{v}_{\mathrm{i}}\right)=1,1 \leq \mathrm{i} \leq \mathrm{p}$

$\mathrm{f}\left(\left(\mathrm{v}_{\mathrm{i}} \mathrm{v}_{1+1}\right)=1,1 \leq \mathrm{i} \leq \mathrm{p}-1\right.$

$\mathrm{f}\left(\mathrm{u}_{\mathrm{p}} \mathrm{u}_{1}\right)=0$

$\mathrm{f}\left(\mathrm{v}_{\mathrm{p}} \mathrm{v}_{1}\right)=1$

It is very clear that the above labeling pattern proved that the difference between the vertices and edges labeled with 0 and 1 differ atmost by 1 .

Hence closed helm graph $\mathrm{CH}_{\mathrm{p}}$ admits MSCL when $\forall p \geq 3$.

Example 3.2: MSCL of a closed helm graph $\mathrm{CH}_{6}$ shown in the Fig 2

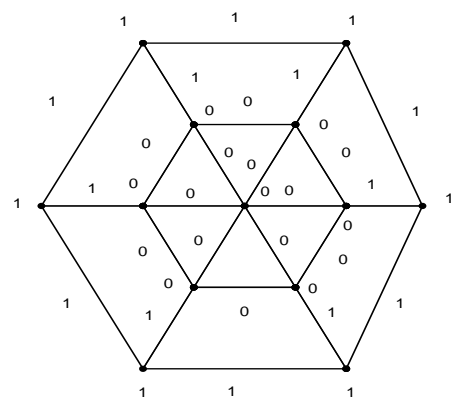

Fig 2

Theorem: 3.3 MSCL of a Gear graph $G_{p}$ when $p$ is odd $\forall p \geq 3$. Proof: Consider a Gear graph $\mathrm{G}_{\mathrm{p}}$ be $\mathrm{G}$

Let $\mathrm{V}(\mathrm{G})=\left\{\mathrm{u}_{0}, \mathrm{v}_{\mathrm{i}}, \mathrm{w}_{\mathrm{i}}: 1 \leq \mathrm{i} \leq \mathrm{p}\right\}$ and $\mathrm{E}(\mathrm{G})=\left\{\left[\left(\mathrm{u}_{0} \mathrm{u}_{\mathrm{i}}\right): 1 \leq \mathrm{i} \leq \mathrm{p}\right] \cup\right.$ $\left[\left(\mathrm{v}_{\mathrm{i}} \mathrm{W}_{\mathrm{i}}: 1 \leq \mathrm{i} \leq \mathrm{p}\right] \cup\left[\left(\mathrm{v}_{\mathrm{i}} \mathrm{W}_{\mathrm{i}+1}\right): 1 \leq \mathrm{i} \leq \mathrm{p}-1\right] \cup\left[\left(\mathrm{w}_{\mathrm{p}} \mathrm{u}_{1}\right)\right]\right\}$ where $\mathrm{u}_{0}, \mathrm{v}_{\mathrm{i}}$ and $\mathrm{w}_{\mathrm{i}}$ be the centre vertex , vertices on a cycle and the centre vertices of a edge of a cycle respectively.

Consider the elements of the vertex set maps either 0 or 1 .

$$
\begin{aligned}
& f\left(u_{0}\right)=0 \\
& f\left(v_{i}\right)=0,\left\{\begin{array}{l}
1 \leq i \leq \frac{p+1}{2} \\
1,\left(\frac{p+3}{2}<i \leq p\right.
\end{array}\right. \\
& f\left(w_{i}\right)=0, f \leq i \leq \frac{p-1}{2} \\
& 1, \frac{p+1}{2}<i \leq p
\end{aligned}
$$

The edge labeling pattern of the above vertex labeling is as follows

$$
\begin{aligned}
& \begin{aligned}
f\left(u_{\mathrm{o}} u_{i}\right)= & \text { of }\left\{\leq i \leq \frac{p+1}{2}\right. \\
& 1, \frac{p+3}{2}<i \leq p
\end{aligned} \\
& f\left(u_{i} u_{i+1}\right)=0\left\{\begin{array}{l}
1 \leq i \leq \frac{p-1}{2} \\
1 \frac{p+1}{2}<i \leq p
\end{array}\right.
\end{aligned}
$$

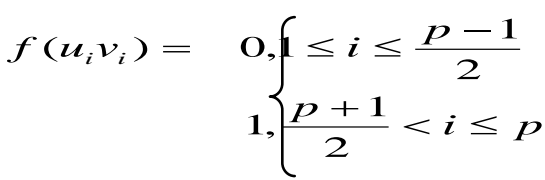

$$
\begin{aligned}
& f\left(u_{1} u_{p}\right)=1
\end{aligned}
$$

It is very clear that the above labeling pattern proved that the difference between the vertices and edges labeled with 0 and 1 differ atmost by 1 .

Hence Gear graph $\mathrm{G}_{\mathrm{p}}$ admits MSCL when $\mathrm{m}$ is odd $\forall p \geq 3$.

Example 3.3: MSCL of a Gear graph $G_{5}$ is shown in the Fig 3.

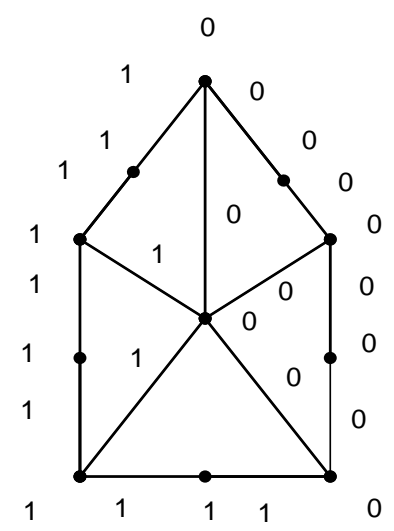

Fig 3

Theorem: 3.4 MSCL of a sunlet graph $S_{p} \forall p \geq 2$.

Proof: Consider a sunlet graph $S_{\mathrm{p}}$ be $\mathrm{G}$.

Consider $\mathrm{V}(\mathrm{G})=\left\{\mathrm{v}_{\mathrm{i}}, \mathrm{u}_{\mathrm{i}}: 1 \leq \mathrm{i} \leq \mathrm{p}\right\}$ and $\mathrm{E}(\mathrm{G})=\left\{\left[\left(\mathrm{u}_{\mathrm{i}} \mathrm{u}_{\mathrm{i}+1}: 1 \leq \mathrm{i} \leq \mathrm{p}-1\right]\right.\right.$ 
$\left.\left.\cup\left[\left(\mathrm{u}_{\mathrm{i}} \mathrm{v}_{\mathrm{i}}\right): 1 \leq \mathrm{i} \leq \mathrm{p}\right]\right] \cup\left[\left(\mathrm{u}_{1} \mathrm{u}_{\mathrm{p}}\right): 1 \leq \mathrm{i} \leq \mathrm{p}\right]\right\}$ where $\mathrm{u}_{\mathrm{i}}$ and $\mathrm{v}_{\mathrm{i}}$ be the vertices on a cycle and pendent vertices respectively.

Consider the elements of the vertex set maps either 0 or 1 .

$\mathrm{f}\left(\mathrm{u}_{\mathrm{i}}\right)=0,1 \leq \mathrm{i} \leq \mathrm{p}$

$\mathrm{f}\left(\mathrm{v}_{\mathrm{i}}\right)=1,1 \leq \mathrm{i} \leq \mathrm{p}$

The edge labeling pattern of the above vertex labeling is as follows

$\mathrm{f}\left(\left(\mathrm{u}_{\mathrm{i}} \mathrm{u}_{\mathrm{i}+1}\right)=0,1 \leq \mathrm{i} \leq \mathrm{p}-1\right.$

$\mathrm{f}\left(\mathrm{u}_{\mathrm{i}} \mathrm{v}_{\mathrm{i}}\right)=1,1 \leq \mathrm{i} \leq \mathrm{p}$

$\mathrm{f}\left(\mathrm{u}_{\mathrm{n}} \mathrm{u}_{1}\right)=0$

It is very clear that the above labeling pattern proved that the difference between the vertices and edges labeled with 0 and 1 differ atmost by 1 .

Hence sunlet graph admits MSCL when $\forall p \geq 3$.

Example 3.4 MSCL of a Sunlet graph $\mathrm{SL}_{8}$ shown in the Fig 4

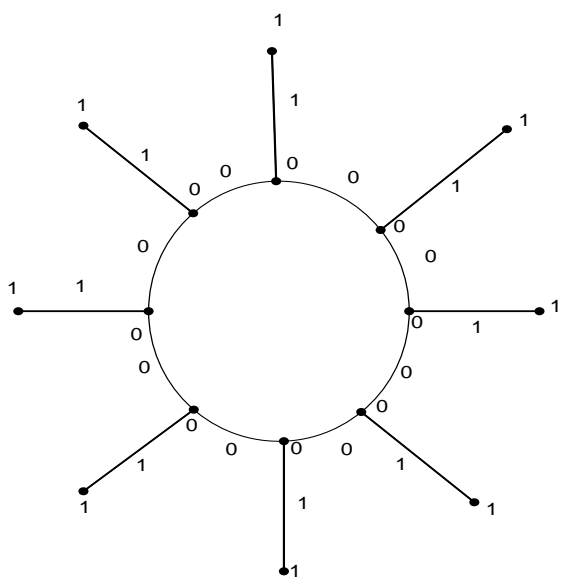

Fig 4

Theorem: 3.5 MSCL of a Fan graph $F_{1, p}$ when $p$ is even $\forall \boldsymbol{p} \geq 2$.

Proof: Consider a Fan graph $\mathrm{F}_{1, \mathrm{n}}$ be $\mathrm{G}$

Let $\mathrm{V}(\mathrm{G})=\left\{\mathrm{u}_{0}, \mathrm{u}_{\mathrm{i}}: 1 \leq \mathrm{i} \leq \mathrm{p}\right\}$ and $\mathrm{E}(\mathrm{G})=\left\{\left[\left(\mathrm{u}_{0} \mathrm{u}_{\mathrm{i}}\right): 1 \leq \mathrm{i} \leq \mathrm{p}\right] \cup\right.$ $\left.\left[\left(\mathrm{u}_{\mathrm{i}} \mathrm{u}_{\mathrm{i}+1}\right): 1 \leq \mathrm{i} \leq \mathrm{p}-1\right] \cup\left[\left(\mathrm{u}_{\mathrm{p}} \mathrm{u}_{1}\right)\right]\right\}$ where $\mathrm{u}_{0}$ and $\mathrm{u}_{\mathrm{i}}$ be the apex vertex and the remaining vertices other than apex respectively.

Consider the elements of the vertex set maps either 0 or 1 .

$$
\begin{aligned}
& f\left(u_{0}\right)=\mathrm{O} \\
& f\left(v_{i}\right)=\left\{\begin{array}{l}
\oint, 1 \leq i \leq \frac{p}{2} \\
1, \frac{p}{2}+1 \leq i \leq p
\end{array}\right.
\end{aligned}
$$

The edge labeling pattern of the above vertex labeling is as follows

$$
\begin{aligned}
& f\left(u_{0} u_{i}\right)=0,\left\{\begin{array}{l}
\leq i \leq \frac{p}{2} \\
1, \frac{p}{2}+1 \leq i \leq p
\end{array}\right. \\
& f\left(u_{i} u_{i+1}\right)=0,\left\{\begin{array}{l}
1 \leq i \leq \frac{p-1}{2} \\
1, \frac{p-1}{2} \leq i \leq p
\end{array}\right.
\end{aligned}
$$

It is very clear that the above labeling pattern proved that the difference between the vertices and edges labeled with 0 and 1 differ atmost by 1 .

Hence Fan graph $\mathrm{F}_{1, \mathrm{p}}$ admits MSCL when $\mathrm{p}$ is even $\forall p \geq 2$.

Example 3.5 MSCL of a Fan graph $F_{1,6}$ shown in the Fig 5

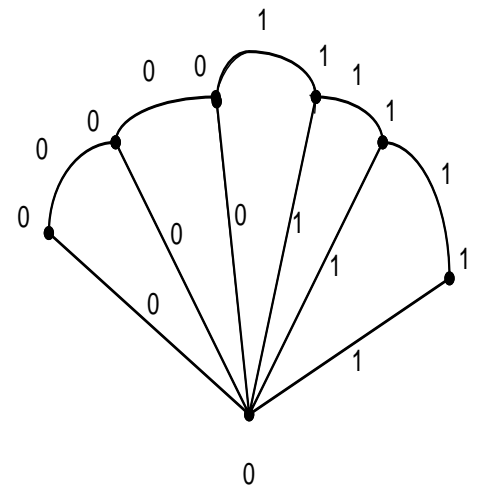

Fig 5

Theorem: 3.6 MSCL of a graph $C_{p} \Theta n K_{1}$ when $n$ is odd $\forall p$. Proof: Consider a graph $\mathrm{C}_{\mathrm{p}} \mathrm{OnK}_{1}$ be $\mathrm{G}$.

Let $\mathrm{V}(\mathrm{G})=\left\{\mathrm{u}_{\mathrm{i}}, \mathrm{v}_{\mathrm{j}}, 1 \leq \mathrm{i} \leq \mathrm{p}, 1 \leq \mathrm{j} \leq \mathrm{pn}\right\}$ and $\mathrm{E}(\mathrm{G})=\left\{\left[\left(\mathrm{u}_{\mathrm{i}} \mathrm{u}_{\mathrm{i}+1}: 1 \leq \mathrm{i} \leq \mathrm{p}\right.\right.\right.$ 1] $\left.\cup\left[\left(u_{i} v_{j}\right): 1 \leq i \leq p, 1 \leq j \leq p n\right]\right\}$ where $u_{i}$ and $v_{j}$ be the vertices on a cycle and pendent vertices respectively.

Consider the elements of the vertex set maps either 0 or 1 .

$\mathrm{f}\left(\mathrm{u}_{\mathrm{i}}\right)=0,1 \leq \mathrm{i} \leq \mathrm{p}$

$\mathrm{f}\left(\mathrm{v}_{\mathrm{j}}\right)=1, \mathrm{j} \equiv 1 \bmod 2$

$0, \mathrm{j} \equiv 0 \bmod 2$,

The edge labeling pattern of the above vertex labeling is as follows

$\mathrm{f}\left(\left(\mathrm{u}_{\mathrm{i}} \mathrm{u}_{\mathrm{i}+1}\right)=0,1 \leq \mathrm{i} \leq \mathrm{p}-1\right.$

$\mathrm{f}\left(\mathrm{u}_{\mathrm{i}} \mathrm{v}_{\mathrm{j}}\right)=1,1 \leq \mathrm{i} \leq \mathrm{p}, \mathrm{j}$ is odd

$\mathrm{f}\left(\mathrm{u}_{\mathrm{i}} \mathrm{v}_{\mathrm{j}}\right)=0,1 \leq \mathrm{i} \leq \mathrm{p}, \mathrm{j}$ is even

It is very clear that the above labeling pattern proved that the difference between the vertices and edges labeled with 0 and 1 differ atmost by 1 .

Hence sun let graph admits MSCL $\forall p$

Example 3.6 MSCL of a graph $C_{p} \Theta n K_{1}$ shown in the Fig 6

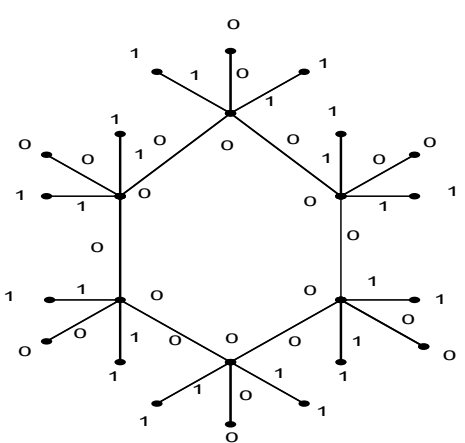

Fig 6

\section{Conclusion}

Here we investigated the MSCL for different cyclic graphs. Further it is an open to all the researchers in this domain to discuss the same labeling technique for various types of graphs.

\section{Acknowledgements}

The authors are very much obliged and extend their gratitude to the reviewers for their valuable feedback and ideas for the 
betterment of article.

\section{References}

[1] Gallian A Dynamic Survey of Graph Labeling Electronic

[2] Journal of Combinatorics, Vol. 18, 2011, pp. 1-219

[3] F. Harary Graph Theory Narosa Publishing House, New Delhi, 1988.

[4] Cahit Cordial Graphs: A Weaker Version of Graceful and Harmonious Graphs Ars Combinatoria, Vol. 23, No. 3, 1987, pp. 201-207.

[5] Ponraj, M.Sivakumar and M.Sundaram, Mean cordial labeling of graphs ,Open journal of Discrete Mathematics, 2(4)(2012), 145-14

[6] A.Nellai Murugan, S.Heerajohn Special Class of Mean Square Cordial Graphs, International Journal of Applied Research 2015; 1(11): 128-131

[7] A.Nellai Murugan, S.Heerajohn Tree Related Mean Square Cordial Graphs ,outreach IX 2016 126-131 ,A multidisciplinary refereed journal

[8] A.Nellai Murugan, S.Heerajohn Cycle related of Mean Square Cordial Graphs, International Journal of research and development organization.

[9] S.Dhanalakshmi and N.Parvathi MSCL related to some acyclic graphs and its rough approximations, Journal of Physics: Conf. Series 1000 (2018) 012040 doi :10.1088/1742-6596/1000/1/01204 